\title{
The Good, the Bad, and the Disruptive of Performance- Based Financing on the Mozambican Health System: Results from a process evaluation
}

\author{
Jessica Gergen \\ Researcher, ThinkWell, Maputo, Mozambique \\ jgergen@visualst.org \\ Yogesh Rajkotia \\ Founder \& CEO, ThinkWell \\ yrajkotia@thinkwell.global \\ Nirmala Ravishankar \\ Program director, ThinkWell \\ nravishankar@thinkwell.global
}

Abstract A significant debate is unfolding around whether performancebased financing $(\mathrm{PBF})$ is a mechanism of achieving broader health systems transformation. This study aims to contribute to this dialogue by assessing how PBF fostered positive, perverse and disruptive effects on the health system in two provinces of Mozambique. The study used qualitative methods to collect data in 24 PBF health facilities from $60+$ health workers and facility administrators. PBF improved the facility's work environment through improved local financial capacity and autonomy, resulting in greater planning. Health workers perceived incentives as a source of motivation, however the allocation of incentives among staff as unfair and lacking transparency. Major improvements in data quality and completeness was observed in facility registers, verified quarterly. However, a heavier workload and enhanced focus on information systems were disruptive to time spent on clinical care. PBF remains a health systems strengthening intervention that results in targeted and program-driven changes that are not yet institutionalized or uniformly applied. Sustaining positive effects will requires greater focus on institutionalizing changes to governance, management structures, and financial autonomy, while enhancing inclusiveness of the demand-side. 
Keywords: Performance-based financing, results-based financing, health systems research, Mozambique, health system reform.

\section{Introduction}

Performance-based financing (PBF) has characteristically been defined as financial incentives for health workers and facilities based on performance on pre-determined measures (Kalk; Paul; Grabosch, 2010; Bonfrer et al., 2014). However, a broader definition has been proposed which more accurately describes PBF as a reform that targets and interacts with the entire health system (Renmans et al., 2017; Meessen et al., 2017; Shroff; Bigdeli; Meissen, 2017; Fretheim et al., 2012; Renmans et al., 2016a). Through this lens, $\mathrm{PBF}$ is an approach that links health facilities and provider payments to the achievement of predefined services and quality measures, but also a mechanism that establishes greater institutional autonomy and governance structures in order to secure a division of functions (purchaser, provider, verifier) (Renmans et al., 2017). In practical terms, the PBF toolk its instruct that schemes be designed to include features that emphasize institutional autonomy, clarified roles (contracting -in), a focus on result-based planning, community participation, division of functions, intensified monitoring, and specific accountability arrangements (Renmans et al., 2017; Fritsche, 2014; Health, 2012; The Aidstar-Two Project, 2011; Tonnen; Van der Wal, 2012). Although every PBF scheme has different objectives and is implemented in varying contexts (Renmans et al., 2017; Witter et al., 2012; De Allegri et al., 2018) a majority incorporate most or all of the aforementioned features. However, PBF is still largely considered a program or intervention by the broader development community and policymakers. Because of this, among the $40+$ PBF schemes globally, most remain in pilot or subnational program status rather than an institutionalized health sector reform (Bertone; Lagarde; Witter 2016; Bonfrer et al., 2014; Peerenboom et al., 2014; Basinga et al., 2011b; Meessen et al., 2017; Shroff; Bigdeli; Meissen, 2017).

Despite the recent surge of interesting PBF evaluations, the impact on reported outcomes varies immensely between programs and contexts, and we still know too little about the mechanisms that lead to changes in outcomes (Renmans et al., 2017; Soucat et al., 2017; Eijkenaar et al., 2013). The PBF enthusiasts have heralded the approach as the starting point for larger health sector reform, hypothesizing that PBF can enhance service delivery, health information systems, supply chain management, financial management, and governance (Meessen; Soucat; Sekabaraga, 2011; Meessen et al., 2017; Shroff; Bigdeli; Meissen, 2017; Paul; Renmans 2017). Skeptics argue that PBF can lead to perverse incentive structures and negative side-effects on non-targeted services and should not be viewed as a "magic bullet" to address all that ails poorly performing health systems (Ireland; Paul; Dujardin, 2011; Renmans et al., 2016b; Paul; Renmans, 2017).

This debate has inspired a growing body of literature exploring the results of PBF and how it operates (Witter et al., 2012; Turcotte-Tremblay et al., 2015; Renmans et al., 
Jessica Gergen (ThinkWell); Yogesh Rajkotia (ThinkWell); Nirmala Ravishankar (ThinkWell).

2016a; Dale, 2014; Paul; Renmans, 2017). Much of this evidence focuses on assessing the impact of PBF on health outputs and outcomes (Basinga et al., 2011a; Borghi et al., 2015; Kambala et al., 2017; Binyaruka et al., 2015; Engineer et al., 2016; Matsuoka et al., 2014; Rudasingwa;Soeters; Basenya, 2017; Rudasingwa; Soeters;Bossuyt, 2014; Skiles et al., 2015; Van de Poel et al., 2016; Rajkotia et al., 2017). While it is important to know whether an intervention has led to gains in healthcare utilization and health outcomes, we also need to understand how PBF processes and factors affect the entire health system, an area that remains understudied (Witter et al., 2013; Meessen et al., 2017; Renmans et al., 2017). While a handful of studies have attempted to explore the effect of PBF on key elements of the health system, such as service delivery, provider motivation, information systems, or access to essential medicines (Matsuoka et al., 2014; Huillery; Seban, 2014; Chimhutu; Lindkvist; Lange, 2014; Lohmann et al., 2017b), few studies have adopted a comprehensive approach to explore the effects of PBF on the health system.

Against this backdrop, this paper explores the wider health system effects of a PBF intervention in the two program regions of Gaza and Nampula. We gathered detailed information on health workers' perceptions of the effects - both good and bad - of the PBF program across the health system. We used the framework developed by Witter et al. (2013) which adapted health system building blocks defined in the World Health Organization's Health Systems Framework to better capture the interactions and changes PBF created at a health facility level in Mozambique (Organization; Witter et al., 2013). In so doing, this study contributes evidence on the perceived effects of PBF on the health system, focusing particularly on how and why these changes occurred.

\section{Description of PBF Pilot Scheme}

In Mozambique, the PBF implementer (Elizabeth Glazer Pediatric AIDS Foundation (EGPAF)), financed by the US President's Emergency Plan for AIDS Relief (PEPFAR) through the Centers for Disease Control and Prevention (CDC), initiated a PBF scheme to accelerate the achievement of maternal and child health (MCH) and HIV-focuses health outcomes in two provinces, Nampula and Gaza. The program began with 19 health facilities in 2011 and was incrementally phased up to 138 health facilities as of mid-2015.

The program established separation of functions. The implementer served as the purchasing agent and fund-holder, while verification of quantity and quality of care is coled by the Provincial Health Office (DPS) and implementer field staff through quarterly visits to each PBF facility (public government-managed workers). The package of services under the PBF scheme is linked to health facility performance across 21 clinical indicators including prevention of mother to child vertical transmission (PMTCT), pediatric HIV, adult HIV care and treatment, tuberculosis, and maternal and child health $(\mathrm{MCH})$. The scheme also includes three quality checklists on hygiene and sanitation, maternal and 
child health (MCH), and HIV/AIDS. Each facility was mandated to establish a managerial committee in charge of planning and managing PBF funds with guidance from the managing NGO (implementer) and district health office (DPS).

Of the performance payments to facilities, $40 \%$ is allocated for reinvestment into the health facility per a pre-approved business plan, while $60 \%$ is distributed as salary topups to all health facility staff according to pre-determined criteria, including tenure at the facility, level of education, attendance, and staff performance review. On average, staff bonuses represent $15-25 \%$ of a monthly salary for health staff with the highest baseline salaries or those working in larger facilities, and 30-50\% of the monthly salary for lowerlevel staff with low baseline salaries or for rural staff in small facilities.

\section{Methods}

To gain an in-depth understanding of the perceptions of health workers and facility managers of the effects of PBF, we used a qualitative research design using in-depth semi-structured interviews and focus group discussions. We triangulated the findings with quantitative verification data. We measured the effect that the PBF program had on the health system, namely service delivery, human resources for health, health financing and governance.

We defined these four health system pillars using Witter's framework (Witter et al., 2013). Witter et al. (2013) posits that the interaction between incentives, institutional changes, accountability efforts, and supporting mechanisms for health workers impacts the organization and performance of the health system (Witter et al., 2013). The resulting framework articulates that all health system building blocks are likely affected by the introduction of PBF, but for simplicity modifies the six into four health system pillars: service delivery (including commodities), human resource, governance (including information systems) and health financing. More recently, the boarder definition and conceptual discourse posited by Renmans et al. (2017) and Soucat et al. (2017) these four of those categories in their definitions of PBF (Soucat et al., 2017; Renmans et al., 2017).

The health workers were asked to describe changes they observed within the health facility since the introduction of PBF and to reflect on the positive, negative, or null effects of PBF across the four pillars. Data was collected at 23 health facilities in Nampula (12) and Gaza (11), 73\% of which were primary health centers and $82 \%$ which were classified as rural or peri-urban. We selected a range of facilities based on size, geographic location (rural, peri-urban, urban), and facility performance data (verified indicator quantities and quality checklist scores). Each facility had participated in the PBF program for a minimum of 6 quarters (18 months).

All interviews were conducted and transcribed in Portuguese, then imported into ATLAS.ti Version 1.0.14 for thematic analysis. Interviews were coded line-by-line and 
Jessica Gergen (ThinkWell); Yogesh Rajkotia (ThinkWell); Nirmala Ravishankar (ThinkWell).

analyzed by the two researchers to identify recurrent themes and variations across responses. Initial themes and sub-codes were organized based on our theoretical model (Figure 1).

Figure 1 - Conceptual Results Framework for Mozambique's PBF Health System Effects
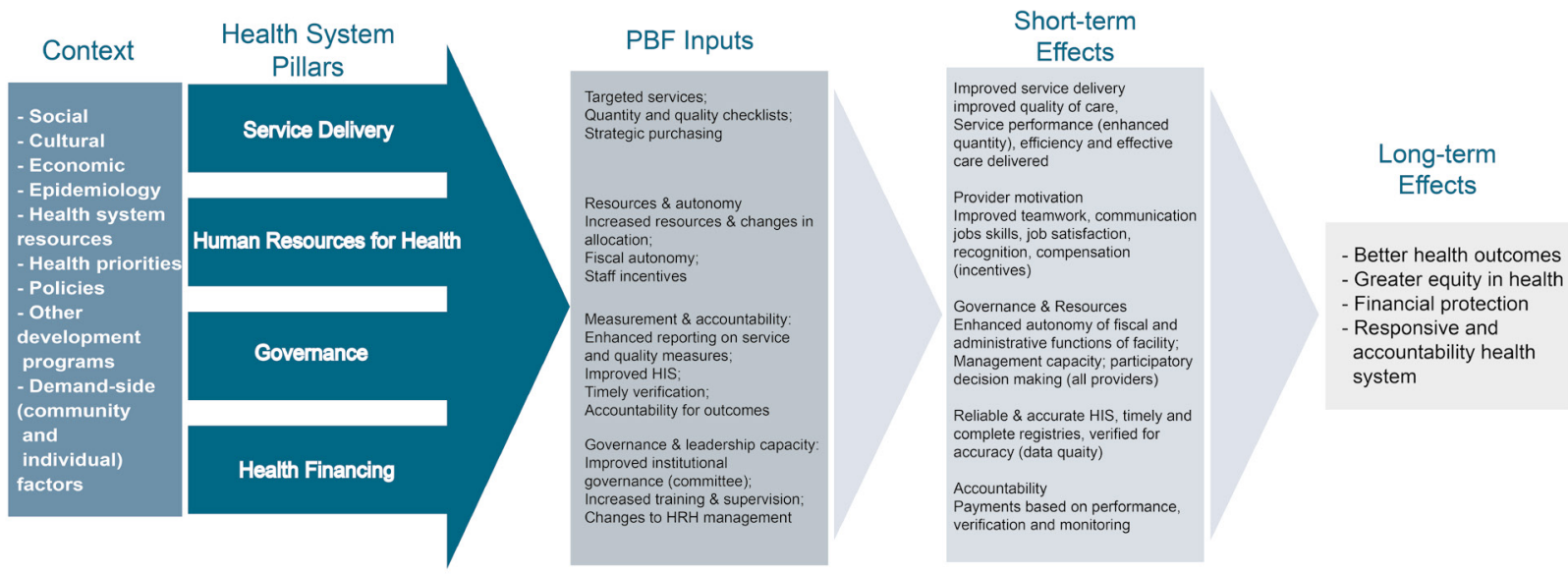

Caption: Theoretical model adapted from Witter et al., 2013.

Abbreviations: HIS, Health Information System; HRH, Human Resources for Health

\section{Quantification Analysis}

Magnitude of effect is a proxy measure to estimate the perceived effect of each change and its attribution to PBF. Magnitude was estimated by the frequency of the code and a coding analysis exercise which assessed and scored each quotation by attribution of the change to PBF (positive and negative, and strength on a three-point scale), saliency and depth (explanation of the change, specificity of the results and self-perceived strength of the change compared to before PBF or in a facility without PBF), other explanations or causes of the observed change (other interventions, contextual changes). While we are aware of the concerns and publications on causality of qualitative work, this analytical technique was used to help organized the top perceived influences of PBF, what was observed and discussed the most by health providers and managers (Maxwell, 2004). We acknowledge that the perceived changes were influenced by PBF, but that contextual components, environmental readiness and other interventions contributed to the changes observed by respondents. Parsing apart attribution to PBF is not achievable with this particularly study design.

\section{Characteristics of respondents}

In each facility, health workers (nurses, medical technicians, and physicians), community health workers and facility administrators were sampled based on their exposure to PBF (minimum of nine months) and availability given we collected data through unannounced facility visits during normal clinic hours. Sixty health workers and facility managers were interviewed individually and a total of 30 health workers participated in focus group discussions (Table 1). Health workers typically participated in the PBF program for an 
average of 9.5 quarters (2.4 years). Semi-structured interview and group discussion guides were used during the interviews, allowing for open dialogue and discussion about the effects of PBF on health system components including service delivery, financing, governance, human resources, access to medicines, and information systems. Data was collected by two Mozambican researchers between November-December 2015.

Table 1 - Profile of Study Participants

\begin{tabular}{|c|c|c|c|}
\hline & $\begin{array}{c}\text { Gaza } \\
\mathrm{N}(\% \text { of } \\
\text { province total) }\end{array}$ & $\begin{array}{l}\text { Nampula } \\
\mathrm{N} \text { (\%of } \\
\text { province } \\
\text { total) }\end{array}$ & $\begin{array}{l}\text { Total } \\
\text { N }(\%)\end{array}$ \\
\hline \multicolumn{4}{|l|}{ Total participants } \\
\hline In-depth Interviews & $29(88 \%)$ & $31(89 \%)$ & $60(88 \%)$ \\
\hline Focus Group Discussions & $4(12 \%)$ & $4(11 \%)$ & $8(12 \%)$ \\
\hline \multicolumn{4}{|l|}{ Sex } \\
\hline Male & $12(41 \%)$ & $15(48 \%)$ & $27(45 \%)$ \\
\hline Female & $17(59 \%)$ & $16(52 \%)$ & $33(55 \%)$ \\
\hline \multicolumn{4}{|l|}{ Professional Position } \\
\hline Nurse (Chief/Head) & $2(7 \%)$ & $1(3 \%)$ & $3(5 \%)$ \\
\hline Nurse (General) & $2(7 \%)$ & $3(10 \%)$ & $5(8 \%)$ \\
\hline Nurse $(\mathrm{MNCH})$ & $7(24 \%)$ & $8(26 \%)$ & $15(25 \%)$ \\
\hline Medical Technician (General) & $12(41 \%)$ & $19(61 \%)$ & $31(52 \%)$ \\
\hline Counselor & $3(10 \%)$ & $0(0 \%)$ & $3(5 \%)$ \\
\hline Administrator/Manager & $3(10 \%)$ & $0(0 \%)$ & $3(5 \%)$ \\
\hline \multicolumn{4}{|l|}{ PBF Exposure (Avg) } \\
\hline & $8.7 \mathrm{Q}$ & 10.2 Q & $9.5 \mathrm{Q}$ \\
\hline Number of Health Facilities & 11 & 12 & 23 \\
\hline \multicolumn{4}{|l|}{ Facility Level } \\
\hline Tertiary & $3(28 \%)$ & $3(25 \%)$ & $6(26 \%)$ \\
\hline Primary & $8(72 \%)$ & $9(75 \%)$ & $17(74 \%)$ \\
\hline \multicolumn{4}{|l|}{ Geographic Region } \\
\hline Urban & $2(19 \%)$ & $2(17 \%)$ & $4(18 \%)$ \\
\hline Rural & $9(81 \%)$ & $10(83 \%)$ & $19(82 \%)$ \\
\hline
\end{tabular}

Abbreviations: $Q$, quarters, equivalent of 3 months.

Caption: The majority of respondents were medical technicians, who assume some managerial role, in addition to diagnosis, treatment, and counseling of all patients, but particularly HIV patients. The second most common respondents were nurses, falling within three professional designations. A head nurse is typically in charge of many of the managerial activities including the completion of the patient registry books. General nurses concentrate on providing wide range of care prescribed to patients by clinician. $\mathrm{MNCH}$ nurses focus on providing preventative and curative care to maternal and child patients, including antenatal care, assisting in deliveries, immediate post-partum care, and contraceptive counseling and prescription. The main function of the lay counselors or Activistas is to provide counseling and referral information for patients in their assigned communities, with special emphasis on $\mathrm{HIV}+$ patients. Information included access points to community support groups (GAACs) and helping patients to find pharmacies to access ARVs. Facility management activities are shared between the facility-based cadre, particularly when the facility is small. The three facility managers listed in Table 1 had no clinical activities and were employed by peri-urban large hospitals. 


\section{Results}

\section{Perceived changes in health system attributed to PBF}

The perceived changes associated with PBF, good, bad and disruptive, varied across the health system pillars. Figure 2 depicts the aggregated quantification results as a heuristic tool to visualize the magnitude of change perceived by facility staff. Figure 3 shows the results from sub-categories within each pillar. The most prominent positive or good changes include infrastructure and available equipment funded by the facility reinvestment funds, integration of care efforts (patient double dipping), information system (quality and completeness of the data), and facility and provider accountability through the verification process (Figure 3). Disruptive changes include task shifting to complete the registry, managerial planning and fiscal autonomy. Inequitable incentive distribution, lack of results-based planning, transparency and communication, and low awareness and buy-in for quality of care checklists affiliated with PBF were perverse changes (Figure 3). The sections below detail our findings from each health system pillar (Table 2 includes illustrative quotations for each).

Figure 2 - Health Worker's Perceived Magnitude of PBF Effects on Health System>

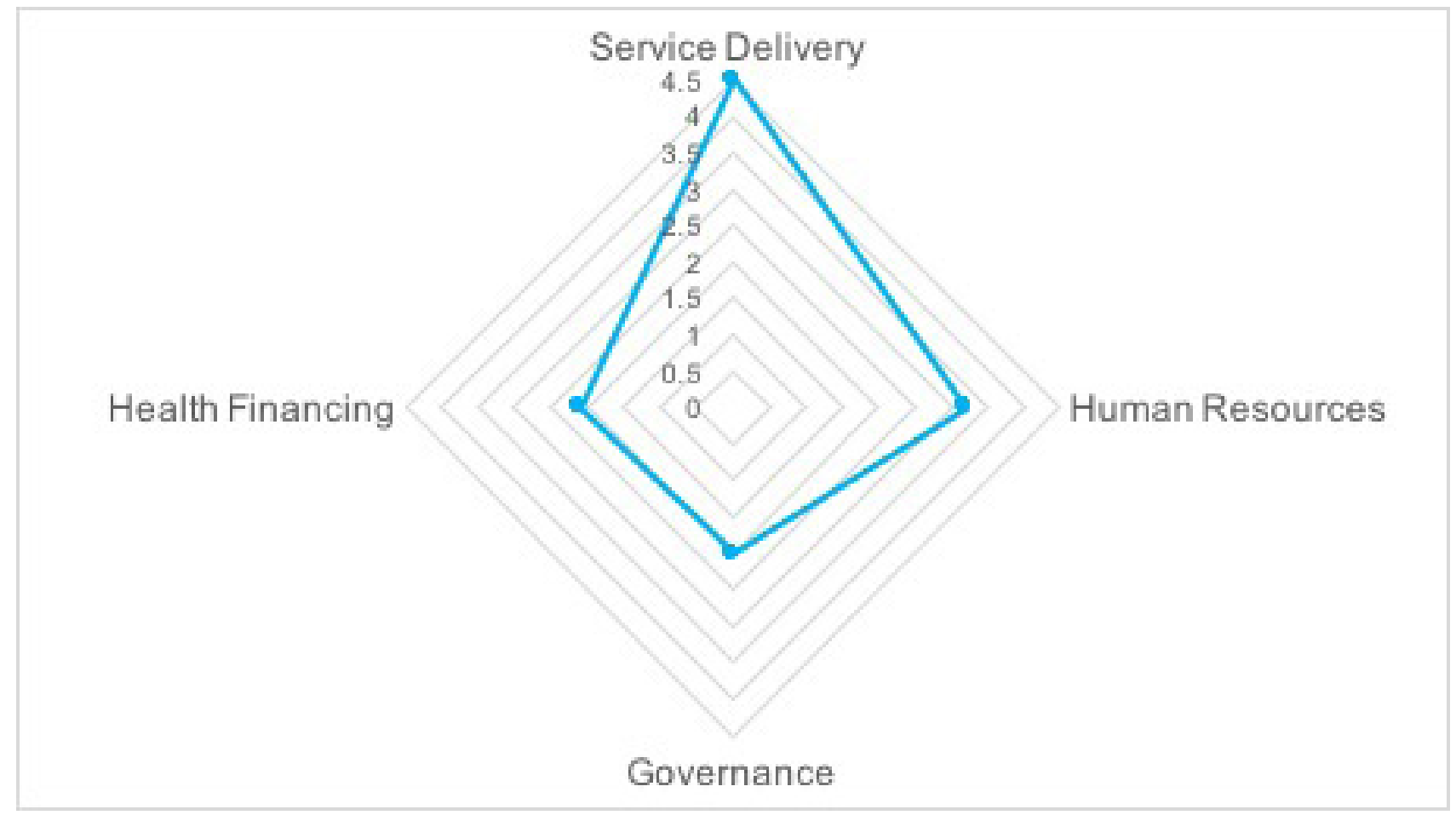

Caption: Magnitude of effect is a proxy measure to estimate the perceived effect of each change and its attribution to PBF. Magnitude estimates are derived from a number of criteria: frequency of the code and associated score of each quotation by attribution of the change to PBF (positive and negative, and strength on a three-point scale), saliency and depth (explanation of the change, specificity of the results and self-perceived strength of the change compared to before PBF or in a facility without PBF), other explanations or causes of the observed change (other interventions, contextual changes). 
Figure 3 - Magnitude of PBF Effects on Health System Pillars (positive \& perverse effects)

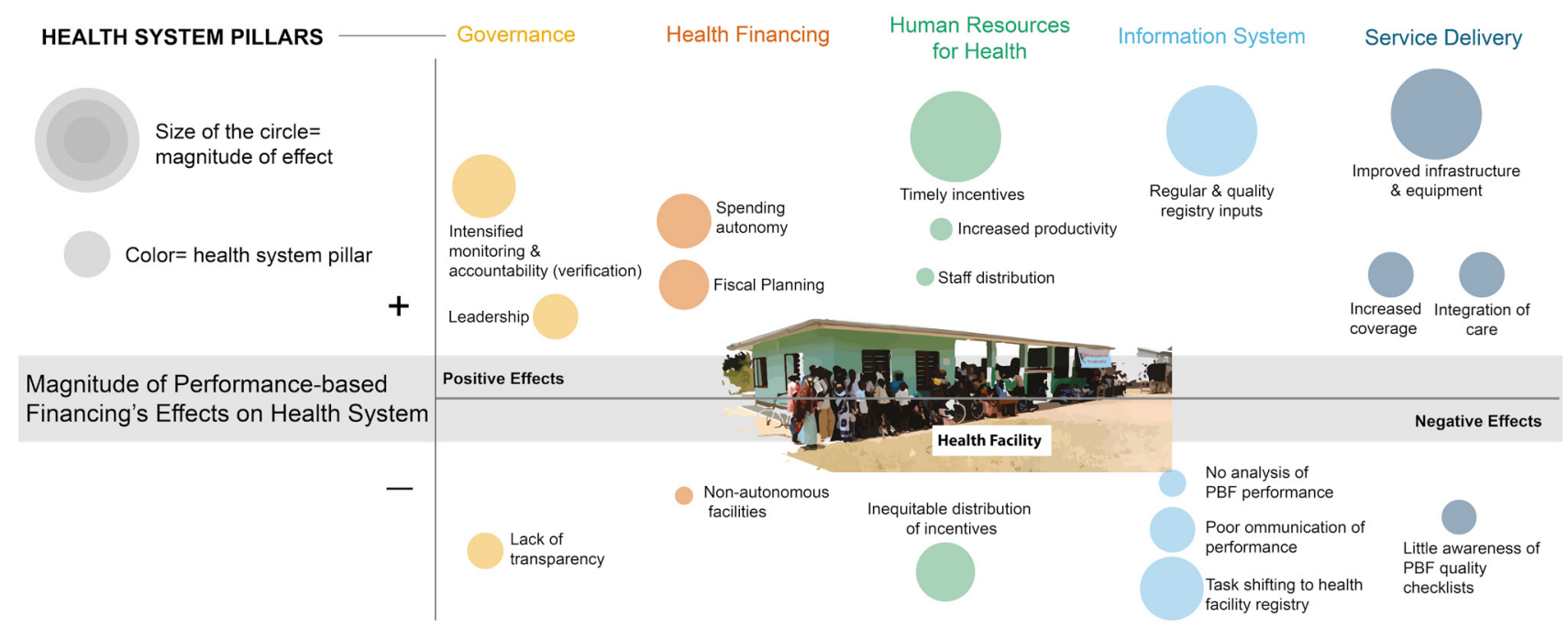

Caption: Magnitude of effect is a proxy measure to estimate the perceived effect of each change and its attribution to PBF. Magnitude estimates are derived from a number of criteria: frequency of the code and associated score of each quotation by attribution of the change to PBF (positive and negative, and strength on a three-point scale), saliency and depth (explanation of the change, specificity of the results and self-perceived strength of the change compared to before PBF or in a facility without PBF), other explanations or causes of the observed change (other interventions, contextual changes).

Table 2 - Illustrative Quotations by Health System Pillar

\begin{tabular}{|c|c|}
\hline $\begin{array}{c}\text { Health System } \\
\text { Pillar }\end{array}$ & Illustrative Quotations \\
\hline \multicolumn{2}{|l|}{$\underline{\text { Service Delivery }}$} \\
\hline $\begin{array}{c}\text { Infrastructure } \mathcal{E} \\
\text { Equipment }\end{array}$ & $\begin{array}{l}\text { "it would take fifteen years for each facility if we did not have the PBF...in the case of the porch, } \\
\text { these comfortable chairs, upgraded bathrooms, yes electrification because we know that a district has } \\
\text { whenever a budget is never enough to meet all our needs, but the PBF has reduced a portion of these } \\
\text { costs but, for me has great impact, not because it improves the health of structures and a portion of its } \\
\text { expenditure rather than to me it has a great impact because it improves the health and also improves } \\
\text { working conditions for health professionals infrastructure, yes" -IDI34_Nampula }\end{array}$ \\
\hline $\begin{array}{l}\text { Integration } \\
\text { of Care }\end{array}$ & $\begin{array}{l}\text { "For my area, I make monthly meetings with APEs, APEs work in the community, and even the } \\
\text { traditional midwives on a monthly basis to coordinate maternity patients and bring the data on the } \\
\text { days they (need to) deliver. We have a meeting that is on the } 25 \text { th and } 15 \text { th of each month and we } \\
\text { enjoy communicating all the activities that we are going to carry out each month, we communicate } \\
\text { to them to make the social mobilization in the communities and we also have (the) Management } \\
\text { Committee participate.. We also meet with community leaders and community leaders."-IDI37- } \\
\text { Nampula } \\
\text { "Now we are functioning as a single stop system, a HIV+ positive pregnant woman, leaves with the } \\
\text { medicine, does everything here,just enter in a single office, and we offer her other services and testing } \\
\text { for her partner. If she happens to go out and go to the pharmacy, its only because of have another } \\
\text { illness, outside... of ... of our treatments... because the medicine is already here at the facility...now } \\
\text { the ladies have a single stop shop"-IDI11_Gaza }\end{array}$ \\
\hline
\end{tabular}




\begin{tabular}{|c|c|}
\hline Quality of Care & $\begin{array}{l}\text { "Yes, to respect patients... we ask(ed) for a porch because we have a space where patient } \\
\text { can be comfortable, for example use it for shade...patients easily get bored in the queue } \\
\text { and can get tired because it can be exposed to the sun and can feel worse than at home.... } \\
\text { any discomfort to a patient who is not well creates more discomfort and the patient may } \\
\text { give up and find that this is not worth it to come to us." -IDI02_Gaza } \\
\text { "Good behaviors have changed in general is this that recently talked ... sometime } \\
\text { colleagues needed to be bribed, and was (delivering) a bad service, patients had long waits } \\
\text { in the queue. So with the PBF, the employee arrives early and on time, they are attentive, } \\
\text { they care for the patient, so these are the behaviors that have changed." -IDI35_Nampula } \\
\text { "yes because I know that I ... this indicator I practically want to sell, it's my fish I want to } \\
\text { sell, I take care of the best possible way it is to be able to buy, if I do not care if this fish has } \\
\text { a little ... get in a little sand so nobody will buy, so I do everything that is for the indicators } \\
\text { to be the same ones of quality, which is to be able to have a benefit." -IDI12_Gaza }\end{array}$ \\
\hline \multicolumn{2}{|l|}{ Information System } \\
\hline Data generation & $\begin{array}{l}\text { "Yes there is improvement because since we knew that the books are visited regularly, } \\
\text { now there is great care in filling the books, we improved enough because even the } \\
\text { communication between us at the facility level in terms of registration book. There were } \\
\text { colleagues before who had problems with data collection because it is difficult to find } \\
\text { time. But now because we learned that the book should be visited by us constantly even } \\
\text { before the supervisor comes, so there was an improvement, yes, yes"-IDI09_Gaza } \\
\text { "We always vaccinated (children) but we did not record all those children we vaccinated } \\
\text { and the data that we sent was not accurate...not that it wasn't real ... it was done..... we } \\
\text { vaccinated the children, but at some point do not we record, and sometimes we record, } \\
\text { but not correctly... before ... it was normal to not keep ... make a bad record, but with this } \\
\text { PBF check the fight is to always register properly." -IDI60_Nampula }\end{array}$ \\
\hline $\begin{array}{l}\text { Analysis and } \\
\text { Communication }\end{array}$ & $\begin{array}{l}\text { "During supervision sessions they check how we were in terms of indicators and when they would } \\
\text { notice that there is an indicator that we are still one little weak, they explained in the sense of } \\
\text { how to improve these indicators, but this in not frequent and is mainly the Management Team." } \\
\text {-IDI21_Gaza } \\
\text { "We have performance graphs for the government indicators like vaccination, but the PBF graphs } \\
\text { are never made or posted for us, so we cannot track our performance. Most of us don't know how } \\
\text { the other units are doing for their performance, only our own unit because we do the registers." } \\
\text {-FGD39_Nampula }\end{array}$ \\
\hline \multicolumn{2}{|r|}{ Health Workforce } \\
\hline Distribution & $\begin{array}{l}\text { "No there has not been changes to the number of clinical staff at the facility, even though PBF has } \\
\text { brought us more work. Our facility does have more Activistas now, working more days, but our staff } \\
\text { is the same."-IDI7_Gaza }\end{array}$ \\
\hline
\end{tabular}




\begin{tabular}{|c|c|}
\hline Remuneration & $\begin{array}{l}\text { "Then theyend up being paid as iftheywereworkingforthe PBF,but there are thosewhoare connected with } \\
\text { the indicators and have to work harderweekly ordaily on what they are doing in relation to the indicators, } \\
\text { and that effects the payment based on performance. Each should reap what they sow." IDI2-Nampula } \\
\text { "Well, tension can exist that I work a lot I have the books but you do nothing but when the time } \\
\text { comes for encouragement you also want to, but let's see what you did, you did nothing. So it ends } \\
\text { up doing what in one way or another those who are not doing, those who are not directly connected } \\
\text { work, do other things that can also benefit the health unit's own performance. So they end up being } \\
\text { involved as if they were working for the PBF" -IDI31_Nampula } \\
\text { "The incentive is very good for us, all of us will have more to bring to our family and to support us. } \\
\text { We see that it helps all of us and because the salary is never enough it has changed our family life." } \\
\text {-IDI19_Gaza }\end{array}$ \\
\hline Training & $\begin{array}{l}\text { "Everyone receives at least one training. EGPAF comes to the facility and provides a day or two of } \\
\text { training for PBF, explaining the formulations of PBF, and sit for example and review some data or } \\
\text { make some tips for improvement"-IDI13_Gaza }\end{array}$ \\
\hline Supervision & $\begin{array}{l}\text { "They (EGPAF) come in helping ... supportive and coaching, help us data also has given some } \\
\text { technical support for PBF, often check the books ... are well filled or try to fix together with us... } \\
\text { mostly it is supervision for the data verification"-IDI45_Nampula }\end{array}$ \\
\hline Communication & $\begin{array}{l}\text { "Communication between units has changed. Communication is better. If there is something we } \\
\text { think is not (working) well we try to correct the colleague, but positively and not in a way that may } \\
\text { insult you... We try to encourage one another and if something is not going well we will solve the } \\
\text { situation together, for instance in our meetings we discussed seeing bad behavior maybe from someone } \\
\text { or something bad that is happening and are able to discuss and come up with a solution." -IDI33_- } \\
\text { Nampula }\end{array}$ \\
\hline \multicolumn{2}{|l|}{ Governance } \\
\hline Leadership & $\begin{array}{l}\text { "Managers are more committed. They are working more, meeting with each other and taking } \\
\text { important decisions. He is traveling to district and other places to do his duties." -IDI26_Nampula } \\
\text { "We received a new head of management committee and there is now more organization and we } \\
\text { feel like they are working as a good representation at district and provincial government." -IDI24_- } \\
\text { Gaza }\end{array}$ \\
\hline Transparency & $\begin{array}{l}\text { "Little, very little announcements or information is shared by our management committee. We are } \\
\text { unsure about how our unit performed, but know that in general we are performing well. Although, } \\
\text { how we do compared to other health facilities we do not know. We could be the best or the worst. I } \\
\text { don't think the worst, but only the committee or DPS will know." -IDI35_Nampula }\end{array}$ \\
\hline $\begin{array}{l}\text { Performance } \\
\text { Monitoring }\end{array}$ & $\begin{array}{l}\text { "So for the month we prepare for the verification team. We know they come, they show up on time } \\
\text { every quarter, and we meet with them a lot during their visit"-FGD01_Gaza } \\
\text { "When EGPAF comes the facility is prepared and we feel we want to perform and provide a good } \\
\text { service to them and the patients" -IDI22_Gaza }\end{array}$ \\
\hline & \\
\hline
\end{tabular}


The Good, the Bad, and the Disruptive of Performance-Based Financing on the Mozambican Health System: Results from a process

Jessica Gergen (ThinkWell); Yogesh Rajkotia (ThinkWell); Nirmala Ravishankar (ThinkWell).

\begin{tabular}{|c|c|}
\hline Autonomy & $\begin{array}{l}\text { "We did not have septic tanks, and we built those pits with the PBF money, for example, when we } \\
\text { wanted to make copies of pre-natal records, we use to depend only on the district direction, but now } \\
\text { we bought a printer and we created a better space. We started a group to do searches for missing } \\
\text { patients, we did it with our PBF money ... that 40\%, we did it with that our PBF money and we } \\
\text { decided... we depended } 100 \% \text { of the district direction before, but now we decide."-IDI43_Nampula }\end{array}$ \\
\hline Fiscal Planning & $\begin{array}{l}\text { "Planning has a space of two more days to bring ideas of what we need to improve more in the } \\
\text { health unit. So there is this space where colleagues, especially the management commission, asks the } \\
\text { needs of each sector to see if we can improve more and more. There is this space, it may not be exactly } \\
\text { in a collective forum but it is sometimes done with the heads of the sectors, they survey the needs and } \\
\text { get answers, yes." -IDI25_Gaza } \\
\text { "Yes, I am on management board. We meet once a month, or we try. We have to submit a plan for } \\
\text { our } 40 \% \text { bonus...how will it be used to improve the facility and quality of care." -IDI14_Gaza } \\
\text { "Almost every quarter is a right plan, after receiving the PBF, the necessary things in so sectors sees } \\
\text { the priorities and buy it, get it ourselves. One priority material for that ... for the sectors, we have } \\
\text { chairs, we have lockers, we have fans, there's a lot here that's bought by PBF background, there's a } \\
\text { lot of change" -FGD04-10_Gaza }\end{array}$ \\
\hline \multicolumn{2}{|c|}{$\underline{\text { Access to Essential Medicines }}$} \\
\hline $\begin{array}{l}\text { Procurement, } \\
\text { supply and } \\
\text { storage }\end{array}$ & $\begin{array}{l}\text { "Medicines are not for purchase with PBF. During the training we were told that. I don't think the } \\
\text { funds are used for medicines, other partners provide medicines" -IDI46_Nampula } \\
\text { "We have the supply and medicines we need for the services of PBF.We had them before. Not many } \\
\text { times have we not had medicines" -IDI18_Gaza }\end{array}$ \\
\hline
\end{tabular}

Caption: None

Service Delivery

\section{Infrastructure \& Equipment}

Every health provider interviewed identified indirect or direct changes observed in facility infrastructure or equipment to PBF (Figure 3). Initially, PBF funds were spent on acute facility needs, like replenishing hygiene and waste disposal supplies, repainting walls, repairing and replacing broken equipment, or repairing infrastructure (e.g. windows, doors, benches).As the PBF program continued, investment was made in large facility improvements like septic tanks, new storage facilities, or electrical rewiring. Facility investments were dictated by the health facility management committee's business plan submitted to the district health office (DPS) quarterly and required approval before funds were received. Purchasing medicines and pharmaceuticals with PBF funds was not permitted.

\section{Integration of care}

Health workers cited feeling a greater sense of coordination in the care they were providing to patients, particularly maternal patients, mothers living with HIV, and infants born to mothers living with HIV. Integration or continuity of care was described as ensuring that patients who were already at the facility received all services or counseling they were eligible for, referred to by one health workers as 'patient double dipping'. 
Integration of PBF services for mothers without HIV included: antenatal care (ANC) visits, facility delivery, post-partum consultation, and family planning (FP) counseling, in addition to timely vaccination for the newborn within 9-12 months and nutritional counseling. For mothers living with HIV, PBF incentivized integrated care through the testing of their partner, antiretroviral (ARV) prophylaxis, antiretroviral therapy (ART) initiation during pregnancy, polymerase chain reaction (PCR) testing within four to eight weeks of birth, rapid HIV testing within nine to 12 months, ART initiation for newborns 0-23 months, and FP counseling after birth. The integration of care was an initiative discussed at monthly or quarterly PBF meetings.

The results of the impact evaluation show significant increases in patients receiving care for PBF indicators compared to control groups (magnitude of effect). Most notably for the services that facilities reported integrated services (Rajkotia et al., 2017).

Figure 4 - Measuring Impact (\% change from baseline) for PBF Indicators
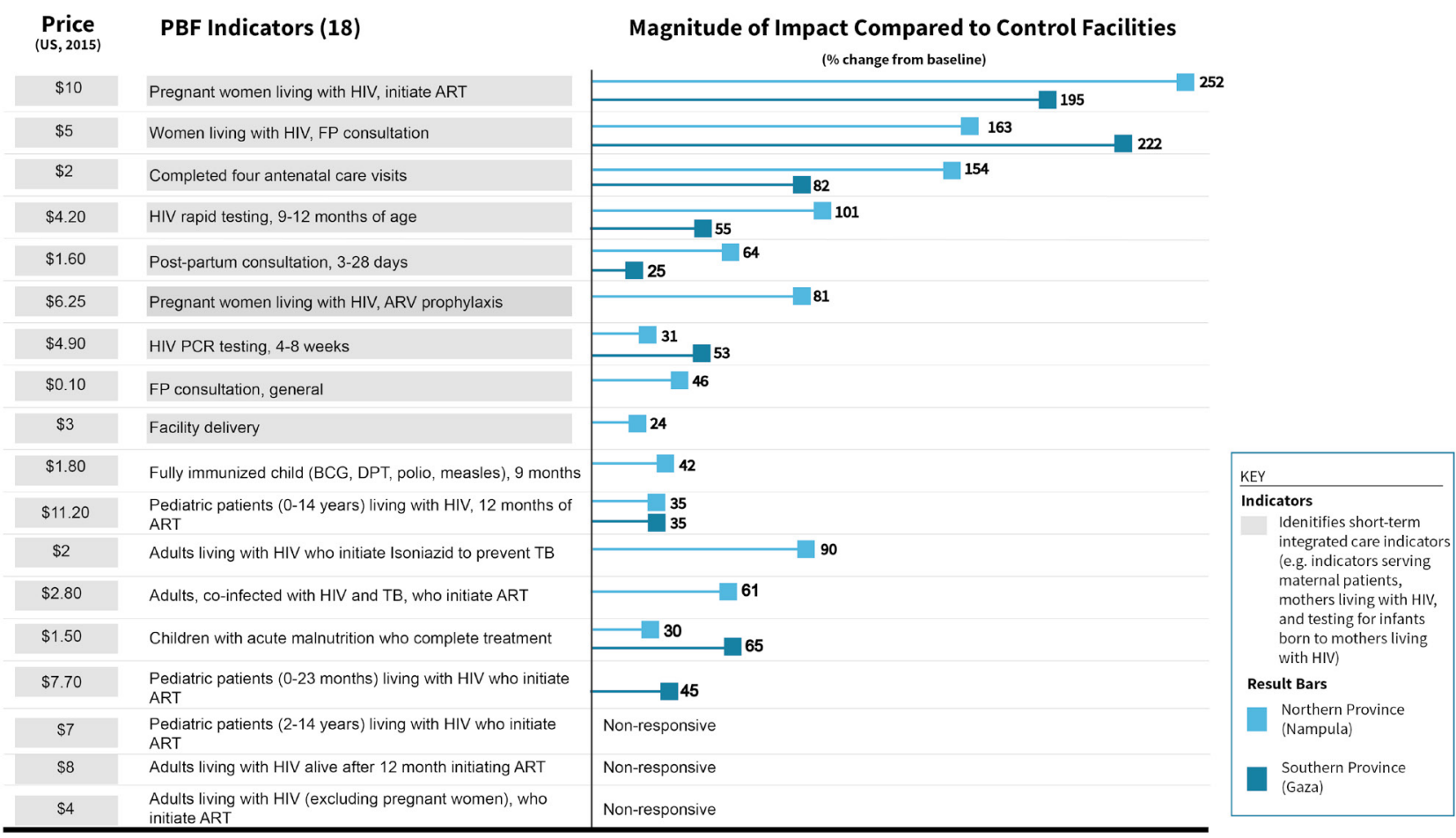

Caption: Results are derived from the impact evaluation completed in 2014 (full results in Rajkotia et al., 2017). Three indicators were dropped from the impact evaluation, which are not displayed here. Magnitude scores were constructed by clustering the magnitude of average treatment effect estimates. A multi-period difference-in-differences (MDID) was applied on the matched sample to obtain average treatment effects

\section{Outreach increases coverage}

Community outreach efforts were amplified by PBF. Activistas, a cadre of community health worker, were reportedly used for outreach and follow-up activities to attract or retain patients, particularly for maternity services and maternal and pediatric patients living with HIV. This strategy was cited as an explanation for the increase in performance on maternal health, PMTCT and pediatric HIV indicators (Figure 4). One 
strategy employed by facilities was to use PBF funds for fuel or repairing vehicles so that Activistas could visit priority patients to ensure they were properly counseled and aware of when they needed to return to the facility. The changes in coverage were not spurred by increased supply-side access (additional operating hours or new clinical services by the health facility).

\section{Quality of care}

Health workers perceived improvements in quality of care via two key observations: reduced waiting times and improved patient comfort. The driver for lower wait times was the adoption of attendance tracking through mandatory sign-in and other mechanisms, increasing health provider accountability and limiting absenteeism. In an effort to increase patient comfort, some facilities used PBF funds to purchase food and water to make the patients and family feel more comfortable during overnight or long stays, and capulanas, decorated cloth worn as a wrap skirt, for women to wear home after giving birth.

The provider's definition of quality contradicts what is measured as performance on PBF quality checklists. The PBF program included three quality checklists, predominately focused on measuring structural attributes of the facility (e.g.presence of supplies, cleanliness of exam room) (Gergen et al., 2017; Josephson et al., 2017). The use and completion of the three PBF quality of care checklists by facilities was rare. Provider's explained that the checklists remained relatively static (same checklists with the same indicators), so if they knew the facility would not score greater than the checklist threshold $(>60 \%)$, then they not to expend the human resources to complete the checklists and review it with the verifier during quarterly visits. Fewer than $15 \%$ of health facilities received a quality bonus from 2014-2015 (University Research Co. and ThinkWell July, 2016).

\section{Information System}

\section{Data generation}

A large majority of health workers reported that patient registries were more complete and the quality of data improved as a response to PBF (Figure 3). Workers felt a responsibility and pressure from managers and facility administrators to complete entries. Prior to PBF, completing facility registers was left until the end of the week, or even month, and the work was not well distributed among service workers. A timelier registry did, however, require significant disruption in task shifting by clinicians away from clinical activities and toward registry completion, and there were reported discrepancies between verified numbers and those submitted by health facility managers in a few instances.

Analysis \& Communication

Health workers do not have the capacity or resources to analyze PBF performance data. According to administrators, performance data was typically only known and understood by facility management participating in the management committee, which 
disrupts the link between enhanced performance and payment. Analysis, including performance forecasts and strategies to increase quantity and quality of PBF services based on past performance, was reportedly only shared with health workers in four of the 24 facilities. In a small number of facilities, graphs of PBF indicator performance were posted to a bulletin board so that health workers were able to review the information. Health workers reported that these visuals were helpful, but that, without strategy meetings and discussion on how to improve current performance, this type of information sharing did little to initiate service or behavior changes.

During quarterly meetings, the verification team often reported on performance of select indicators, but this analysis was incomplete and was not used as a mechanism to stimulate performance improvements by health workers. In general, there was a low level of awareness amongst health workers on facility-level performance of indicators they were not directly responsible for and little discussion of how to improve performance based on historical analyses.

\section{Human Resources}

\section{Distribution}

Health workers and administrators perceived little change in the distribution of health workers to PBF facilities (Figure 3). Intervention facilities were reportedly favored by health workers and formal requests for transfers were common. Anecdotally, health workers felt their colleagues had stayed at PBF facilities longer than they would have at non-PBF facilities (retention), however quantitative data concerning human resource retention rates for PBF and non-PBF facilities is not available.

\section{Remuneration}

Salary top-ups or bonuses were perceived very positively. Health workers often spoke of incentives as a source of motivation and freedom to support their families. The salaries of health workers in Mozambique remain low, on average (2014) a nurse will receive between 4000-7000 MTs (USD 60-105) per month, a medical technician will receive 7000-9000MTs (US\$105-138, double the GDP per capita) per month, depending on tenure, education level, and other adjustments. Many health workers mentioned that, in the absence or withdrawal of PBF, their base salaries would be insufficient to support themselves and their families. In some cases, the base salaries provided by the provincial budget were late by two or three quarters and the PBF bonuses served as the entire salary.

However, the distribution of incentives was often contentious and source of mistrust among colleagues. All health facility staff received a 'piece of the pie' even if they do not work on PBF indicators, including non-clinicians (e.g. janitors, administrative staff). In a third of the facilities, the PBF incentive amount received by each health provider was posted on the health facility bulletin, but this made the sense of unfairness more apparent, 
Jessica Gergen (ThinkWell); Yogesh Rajkotia (ThinkWell); Nirmala Ravishankar (ThinkWell).

and created further tension between health workers in different professional positions and service types.

\section{Training and skills building}

Neither additional clinical training nor improved adherence to clinical guidelines were reported, however, each provider received the training, which detailed the programmatic components and purpose of the PBF program, at least once. Every participant could describe PBF and the basic tenets of the program including the reporting, verification, and incentive distribution percentages, however components coordinated by the management committee like the quality checklist, payment formula or planning for facility funds were either not communicated or retained by workers.

\section{Supervision}

The presence of district supervisors or utilization of supportive supervision techniques was not affected or promoted by PBF.Verification, as one form of supervision and perceived as a strong accountability mechanism, changed significantly. Workers felt that their achievements were measured and recognized through verification.

Performance reviews were designed to be a supervisory management tool. These reviews were intended to be conducted by facility management on an annual basis as part of the criteria for individual PBF payment calculations. The application and use of individual performance reviews was scattered and few health workers recall having one completed for themselves or their colleagues.

\section{Governance}

\section{Leadership \& Transparency}

Health workers perceived notable changes in facility leadership with relation to the monthly and quarterly committee meetings (only inclusive of senior facility management). Each participating facility must have an active Health Facility Management Commission (HFMC) responsible for reviewing the facility performance (quality of care and quantity of services) quarterly, resolving problematic management and policy issues, and lobbying for and assisting with resource mobilization. Although health workers were aware that the facility management committees developed a business plans quarterly, they were not part of these discussions nor decision-making processes about facility investments and strategies for increasing PBF services.

Enhanced transparency through participation and communication about the PBF to communities, was not reported. Transparency of facility-level performance data to external institutions was also lacking. For instance, PBF data was not available for facilities to compare nearby facilities' performance, for programs and researchers from partner NGOsto view, nor 
available to national government or a global audience through existing data platforms like the RBF portal.( The World Bank Group, <https://www.rbfhealth.org/>).

\section{Performance Monitoring}

The verification process is the most pertinent change in performance monitoring at the facility level (Figure 3). The reliability and timeliness of the verification process conducted by the implementing NGO and DPS increased the amount of pressure and accountability the facility staff felt towards preparing a complete and accurate registry. Although penalties for false reporting were rare, health workers were aware of this possible adverse event. Although the verification team did not present or broadly discuss the facility's performance outside of the facility management team, the frequency and time spent at the facility every quarter served as an effective performance monitoring technique.

\section{Health Financing}

\section{Resource allocation}

Financial autonomy was perceived as a key change and driver of program impact. Facility administrators and managers (typically chief nurses and senior medical technicians) had a positive disposition toward having the autonomy to manage their own 'pot' of money based on a process of strategic planning and coordination with the provincial health office and implementer. Conversely, staff at non-autonomous facilities, where district health offices receive the facility's funds and then distribute the staff incentives and facility investments, felt that the districts often delayed their incentives and that they did not receive the full amount earned.

Health workers noted an increase in resource allocation with the introduction of a more robust and deliberate planning process for facility investment and spending. The increase in financial resources due to the PBF facility funds resulting in the physical changes in infrastructure and supplies is the most frequently cited effect. For many of the rural and/or small facilities, the PBF incentive for facility reinvestment is $40-50 \%$ of the budget received by the province/central level through input-based financing. Hence, the impact PBF money had on health facilities purchasing power was perceived as very significant.

\section{Discussion}

As more donors and country governments in LMICs start embracing PBF as an approach to boost performance in the health sector, there have been repeated calls for rigorous evaluations to grow the evidence base on PBF (Eldridge; Palmer, 2009; Witter et al., 2012; Renmans; Holvoet; Criel, 2017; Renmans et al., 2016b; Paul; Renmans, 2017). 
While the body of research on PBF has grown significantly in the past few years, recent reviews of the literature have found that, firstly, the evidence about the impact of PBF programs on health system outputs and health outcomes is mixed and, secondly, a lot remains unknown about how PBF acts on the health system (Witter et al., 2012; Renmans et al., 2016a; Paul; Renmans, 2017). This study speaks to the second observation, using a PBF program in Mozambique to understand how PBF influences actors, institutions, and processes that comprise the health system. The approach we adopted of interviewing health workers to capture their perceptions is similar to what others have used to explore key aspects of PBF programs, such as the implementation process and the effect of PBF on staff motivation (Bhatnagar; George, 2016; Kalk; Paul;Grabosch, 2010). Our application of evaluating PBF across the entire health systems pillars, as defined by Witter et al. (2013), about the changes attributed to the PBF program is novel. While other articles have documented the perceived effects of PBF interventions on individual building blocks like service delivery, (Bonfrer;Van de Poel;Van Doorslaer, 2014; Chimhutu et al., 2015; Skiles et al., 2015; Flink et al., 2016; Kalk; Paul; Grabosch, 2010; Paul, 2009; Bhatnagar; George, 2016) human resources for health,(Matsuoka et al., 2014; Engineer et al., 2016; Lohmann et al., 2017a; Lohmann et al., 2018) and health information system, (Rusa et al., 2009; Kalk; Paul; Grabosch, 2010) no study to date has used a comprehensive health systems lens to systematically explore the perceived effects of PBF on all pillars.

The results from the study show that health workers reported PBF as having had good, bad and disruptive perceived effects on all pillars at variable magnitudes. Overall, the PBF scheme was perceived to have had the greatest effect in the areas of service delivery, health workforce, and information systems. It had more modest effects on health financing and governance, and no effect on the supply of pharmaceutical commodities (by design).

In the area of service delivery, health workers believed the PBF program has resulted in an expansion of service coverage, which is not surprising given that an impact evaluation for the PBF program in Mozambique found increases in a range of health outputs, (Rajkotia et al., 2017) and other evaluation of PBF pilots that showed similarly positive perceived effects on healthcare utilization (Basinga et al., 2011a; Bonfrer et al., 2014; Engineer et al., 2016). Health workers felt the PBF program had strengthened integration of care and the nature of the interaction between health workers and patients. This is similar to findings in Rwanda and Cambodia, where PBF schemes led to an improvement in the interaction between health workers and patients (Kalk; Paul; Grabosch, 2010; Khim; Annear, 2013; Skiles et al., 2015). What emerged most notably is how much health workers appreciation for the infrastructure improvements that health facilities have been able to undertake thanks to the PBF scheme. Health workers were largely unaware of the PBF quality components, including the checklists themselves, and the payment formula based on the facility's quality score. Quality checklists also need to be more process driven, measuring multiple components of quality, including process and outcomes of care. Understanding advances in maternal and child health quality efforts 
may be a great source of cross-learning, especially because most PBF programs focus on quality of care in MCH (Gergen et al., 2017; Josephson et al., 2017).

In the domain of human resources for health, the PBF payments reportedly increased health worker motivation. This finding is in line with other studies that showed documented positive responses by health workers to the increase in their remuneration (Kalk; Paul; Grabosch, 2010; Bertone; Lagarde; Witter, 2016; Skiles et al., 2015; Lohmann et al., 2017b, Lohmann et al., 2017a). PBF was also credited for improving staff retention rates, as was the case in Cambodia (Matsuoka et al., 2014). However, health workers in Mozambique expressed concerns about the fairness of how the PBF funds were distributed amongst health workers, which echoes concerns by health workers in Tanzania (Chimhutu et al., 2016), Cambodia (Khim; Annear, 2013), DRC(Fox et al., 2014) and Benin (Paul; Sossouhounto; Eclou, 2014). Unlike other PBF programs, where the incentive to improve performance led managers to increase training and supportive supervision for health workers (Bhatnagar; George, 2016), study participants in Mozambique reported receiving limited clinical training and supportive supervision external to the PBF verification and managerial committee meetings. This finding reiterates the need to integrate broader supervision, such as supportive supervision mechanisms, within the PBF design to further enhance facility and provider performance, clinical adherence, patient-provider communication and respectful care. PBF did not change the composition within the facilities, which is likely due to the fact that distribution of health workers is decided by the provincial and central government based on catchment population estimates.

The PBF program strengthened the health information system at the facilitylevel. Similar positive effects of the PBF program on health information captured at the facility level have been reported in Burundi (Peerenboom et al., 2014). However, these improvements came at a cost. Faced with a trade-off between delivering more clinical services and spending time maintaining the register books, health workers reported shifting their focus from the former to the latter because of the PBF verification. There were also notes on discrepancies between verification and reported numbers. Health workers were not concerned about the discrepancies because although penalties were intended to be applied, no health facility ever received penalties during the program's tenure. Instead the verified would note it and warn the health facility manager. This is similar to Rwanda, where Kalk; Paul; Grabosch (2010) found evidence of task-shifting towards record maintenance, and in Burkina Faso (Kalk; Paul;Grabosch, 2010; TurcotteTremblay et al., 2017)

Further, the PBF program was credited with improving some governance and managerial practices at the facility-level, especially frequent business planning meetings. However, the absence of monthly PBF performance review meetings and the perceived unfairness in incentive distribution made staff and team relations tense at some facilities. Similar to the experience in Cambodia, the PBF and operational cost disbursement were faster than the $\mathrm{MoH}$ budget endowment, ensuring timely disbursement of the incentives on the basis of their performance and strengthened capacity for financial management 
(Matsuoka et al., 2014; De Allegri et al., 2018). Although the governance structures and processes at the facility level were changed, they could be improved significantly using a more participatory, transparent approach (De Allegri et al., 2018; Seppey et al., 2017).

With respect to health financing, health workers credited the PBF program with increasing the fiscal autonomy. This resulted in greater planning at the facility-level on how the PBF funds would be reinvested into the facility (De Allegri et al., 2018). However, these decisions were made largely by the facility managers, with little input from the health workers. Most health workers interviewed were absent from the allocation and resource mobilization processes but keenly aware of the results of these investments, namely the structural and equipment changes. This concept of performance-based financing was broadly and shallowly understood by nearly all health workers, and the link between taking action and planning for increasing service in order to get a bigger bonus was not as clear. This is a core gap in the theory of change and operationalization of PBF, workers and managers both need to understand that performance is directly tied to payments in order to driven performance. Understanding the payment formula would be the first step, however there is significant heterogeneity in the payment formulas, as well as complexity in the calculations.

The methodology adopted in this study of capturing information on the PBF health system perceived effects through semi-structured interviews with health workers has a number of limitations. First, respondents were selected in collaboration with facility management, which could have led to a bias sample of well-adjusted or positive health workers. Moreover, the sample only focused on the supply-side and did not capture beneficiary perceptions or validate any of the changes health providers attributed to PBF. Although the evaluation was conducted by an independent evaluator (ThinkWell), the implementer and occasionally DPS accompanied our data collectors to the facility to facilitate the introduction and coordination of the interviews. The interview guide was open-ended, but all health workers were probed on changes attributed to PBF for all pillars to ensure we were able to capture the perceived effects across the entire system but could have introduced biasin health worker responses.

\section{Conclusion}

The changes described demonstrate that PBF has the potential to go well beyond health worker motivation and enhance service delivery to broadly strengthen the health system. However, to achieve its potential, a number of things need to happen. First, program designers and implementers will need to think more critically about how a combination of PBF incentives and technical support can catalyze and institutionalize managerial governance changes at the facility level. Managerial changes and organizational culture should incorporate managerial autonomy to ensuring that the facilities are properly staffed, have adequate supplies, and completed registers. Moreover, program implementers should consider a more robust and active long-term sustainability strategy to institutionalize the 
program into provincial and national health offices while decreasing control by an external NGO. The Mozambican PBF program failed at numerous level of institutionalization and gaining buy-in from government and other actors, and subsequently the program was ended in 2017 (Gergen; Falcao; Rajkotia, 2018), which reflects the experience documented across many programs (Shroff; Bigdeli; Meissen, 2017; Seppey et al., 2017). Second, the program must be designed such that an increasing proportion of the health facility budget is output-based versus input-based to keep the focus on performance. Third, strengthening the participation of the supply-side could support the strength of PBF's positive effects on the health system.

\section{References}

BASINGA, Paulin et al.Effect on maternal and child health services in R wanda of payment to primary health-care providers for performance: an impact evaluation. Lancet 377 (9775):1421-8. doi:10.1016/S0140-6736(11)601773, 2011a.

BASINGA, Paulin et al. Effect on maternal and child health services in Rwanda of payment to primary healthcare providers for performance: an impact evaluation. The Lancet 377 (9775):1421-1428, $2011 \mathrm{~b}$.

BERTONE, Maria Paola; LAGARDE, Mylene;WITTER, Sophie. Performance-based financing in the context of the complex remuneration of health workers: findings from a mixed-method study in rural Sierra Leone. BMC Health Serv Res 16 (1):286. doi: 10.1186/s12913-016-1546-8, 2016.

BHATNAGAR, Aruni; GEOR GE, Asha. Motivating health workers up to a limit: partial effects of performancebased financing on working environments in Nigeria. Health Policy Plan. doi: 10.1093/heapol/czw002, 2016.

BINYARUKA, Peter et al. Effect of Paying for Performance on Utilisation, Quality, and User Costs of Health Services in Tanzania: A Controlled Before and After Study. PLoS One 10 (8):e0135013. doi: 10.1371/journal. pone.0135013, 2015.

BONFRER, Igna et al. Introduction of performance-based financing in burundi was associated with improvements in care and quality. Health Aff (Millwood) 33 (12):2179-87. doi: 10.1377/hlthaff.2014.0081, 2014.

BONFRER, Igna;VAN DE POEL, Ellen;VAN DOORSLAER, Eddy. The effects of performance incentives on the utilization and quality of maternal and child care in Burundi. Soc Sci Med 123:96-104. doi: 10.1016/j. socscimed.2014.11.004, 2014.

BORGHI, Josephine. et al. Protocol for the evaluation of a free health insurance card scheme for poor pregnant women in Mbeya region in Tanzania: a controlled-before and after study. BMC Health Serv Res 15:258. doi: 10.1186/s12913-015-0905-1, 2015.

CHIMHUTU,Victor; LINDKVIST, Ida; LANGE, Siri. When incentives work too well: locally implemented pay for performance (P4P) and adverse sanctions towards home birth in Tanzania - a qualitative study. BMC Health Serv Res 14:23. doi: 10.1186/1472-6963-14-23, 2014.

CHIMHUTU, Victor et al. The inescapable question of fairness in Pay-for-performance bonus distribution: a qualitative study of health workers' experiences in Tanzania. Global Health 12 (1):77. doi: 10.1186/s12992-0160213-5, 2016.

CHIMHUTU,Victor et al. Introducing payment for performance in the health sector of Tanzania - the policy process. Global Health 11:38. doi: 10.1186/s12992-015-0125-9, 2015.

CORDAID- SINA. PBF in Action:Theories and Instruments, PBF Course Guide. The Hague: Cordaid.

DALE, Elina. 2014. Performance-Based Payments, Provider Motivation and Quality of Care in Afghanistan. Doctoral Dissertation, 2012. 
The Good, the Bad, and the Disruptive of Performance-Based Financing on the Mozambican Health System: Results from a process

evaluation

Jessica Gergen (ThinkWell); Yogesh Rajkotia (ThinkWell); Nirmala Ravishankar (ThinkWell).

DE ALLEGRI, Manuela et al. Unraveling PBF effects beyond impact evaluation: results from a qualitative study in Cameroon. BMJ Glob Health 3 (2):e000693. doi: 10.1136/bmjgh-2017-000693, 2018.

EIJKENAAR, Frank et al. Effects of pay for performance in health care: a systematic review of systematic reviews. Health Policy 110 (2-3):115-30. doi: 10.1016/j.healthpol.2013.01.008, 2013.

ELDRIDGE, Cleaver; PALMER, Natasha. Performance-based payment: some reflections on the discourse, evidence and unanswered questions. Health Policy Plan 24 (3):160-6. doi: 10.1093/heapol/czp002, 2009.

ENGINEER, Cyrus et al. Effectiveness of a pay-for-performance intervention to improve maternal and child health services in Afghanistan: a cluster-randomized trial. Int J Epidemiol 45 (2):451-9. doi: 10.1093/ije/dyv362, 2016.

FLINK, Ilse et al. Targeting the poorest in a performance-based financing programme in northern Cameroon. Health Policy Plan 31 (6):767-76. doi: 10.1093/heapol/czv130, 2016.

FOX, Sarah et al. Paying health workers for performance in a fragmented, fragile state: reflections from Katanga Province, Democratic Republic of Congo. Health Policy Plan 29 (1):96-105. doi: 10.1093/heapol/czs138, 2014.

FRETHEIM,Atle. et al. Performance-based financing in low- and middle-income countries: still more questions than answers. Bull World Health Organ 90 (8):559-559A. doi: 10.2471/BLT.12.106468, 2012.

FRITSCHE, Gyorgy Bela; SOETERS, Robert; MEESSEN, Bruno. Performance-based Financing Toolkit. World Bank, 2014.

GER GEN, Jessica. et al. Quality of Care in Performance-Based Financing: How It Is Incorporated in 32 Programs Across 28 Countries. Glob Health Sci Pract 5 (1):90-107. doi: 10.9745/GHSP-D-16-00239, 2017.

GERGEN, Jessica; FALCÃO, Joana; RAJKOTIA, Yogesh. Stunted Scale-up of Performance-Based Financing Program on HIV and Maternal/Child Health Services in Mozambique - a Policy Analysis African Journal of AIDS Research, 2018.

HUILLERY, Elise; SEBAN, Juliette. Performance-based Financing, Motivation and Final Output in the Health Sector: Experimental Evidence from the Democratic Republic of Congo, 2014.

IRELAND, Megan; PAUL, Elizabeth; DUJARDIN, Bruno. Can performance-based financing be used to reform health systems in developing countries? Bull World Health Organ 89 (9):695-8. doi: 10.2471/BLT.11.087379, 2011.

JOSEPHSON, Erik et al. How do performance-based financing programmes measure quality of care? A descriptive analysis of 68 quality checklists from 28 low- and middle-income countries. Health Policy Plan. doi: 10.1093/heapol/czx053, 2017.

KALK, Andreas; PAUL, Fritsche; GRABOSCH, Eva. Paying for performance' in Rwanda: does it pay off? Trop Med Int Health 15 (2):182-90. doi: 10.1111/j.1365-3156.2009.02430.x, 2010.

KAMBALA, Christabel et al. Perceptions of quality across the maternal care continuum in the context of a health financing intervention: Evidence from a mixed methods study in rural Malawi. BMC Health Serv Res 17 (1):392. doi: 10.1186/s12913-017-2329-6, 2017.

KHIM, Kvathanak; ANNEAR, Peter; Strengthening district health service management and delivery through internal contracting: lessons from pilot projects in Cambodia. Soc Sci Med 96:241-9. doi: 10.1016/j. socscimed.2013.02.029, 2013.

LOHMANN, Julia et al. How does performance-based financing affect health workers' intrinsic motivation? A Self-Determination Theory-based mixed-methods study in Malawi. Soc Sci Med 208:1-8. doi: 10.1016/j. socscimed.2018.04.053, 2018.

LOHMANN, Julia et al. Measuring health workers' motivation composition: validation of a scale based on SelfDetermination Theory in Burkina Faso. Hum Resour Health 15 (1):33. doi: 10.1186/s12960-017-0208-1, 2017a. 
LOHMANN, Julia et al. The money can be a motivator, to me a little, but mostly PBF just helps me to do better in my job. An exploration of the motivational mechanisms of performance-based financing for health workers in Malawi. Health Policy Plan. doi: 10.1093/heapol/czx156, 2017b.

MATSUOKA, Satoshi et al. Performance-based financing with GAVI health system strengthening funding in rural Cambodia: a brief assessment of the impact. Health Policy Plan 29 (4):456-65. doi: 10.1093/heapol/czt030, 2014.

MAXWELL, Joseph. Causal Explanation, Qualitative Research, and Scientific Inquiry in Education. Educational Research:p2-11, 2004.

MEESSEN, Bruno; SOUCAT, Anges; SEKABARAGA, Claude. Performance-base financing: just a donor fad or a catalyst towards comprehensive health-care reform? Bulletin World Health Organization, 2011.

MEESSEN, Bruno et al. From Scheme to System (Part 1): Notes on Conceptual and Methodological Innovations in the Multicountry Research Program on Scaling Up Results-Based Financing in Health Systems. Health Systems \& Reform, 2017.

PAUL, Elisabeth.; RENMANS, Dimitri. Performance-based financing in the heath sector in low- and middleincome countries: Is there anything whereof it may be said, see, this is new? Int J Health Plann Manage, 2017. doi: 10.1002/hpm.2409.

PAUL, Elisabeth; SOSSOUHOUNTO, Nadine.; ECLOU, Dieudonne. Local stakeholders' perceptions about the introduction of performance-based financing in Benin: a case study in two health districts. Int J Health Policy Manag 3 (4):207-14, 2014. doi: 10.15171/ijhpm.2014.93.

PAUL, Elisabeth. Health Worker Motivation and the Role of Performance Based Finance Systems in Africa: Qualitative Study on Health Workers Motivation and the Rwandan Performance Based Finance Initiative in District Hospitals, 2009.

PEERENBOOM, Peter Bob et al. Good governance in the Burundi health sector financial reform. Sante Publique 26 (2):229-40, 2014.

RAJKOTIA, Yogesh et al. The effect of a performance-based financing program on HIV and maernal/child health services in Mozambique-an impact evaluation. Health Policy Plan 32 (10):1386-1396. doi: 10.1093/ heapol/czx106, 2017.

RENMANS, Dimitri; HOLVOET, Nathalie; CRIEL, Bart. Combining Theory-Driven Evaluation and Causal Loop Diagramming for Opening the 'Black Box' of an Intervention in the Health Sector:A Case of PerformanceBased Financing in Western Uganda. Int J Environ Res Public Health 14 (9). doi: 10.3390/ijerph14091007, 2017.

RENMANS, Dimitri et al. Performance-based financing: the same is different. Health Policy Plan 32 (6):860868, 2017. doi: 10.1093/heapol/czx030.

RENMANS, Dimitri et al. Opening the 'black box' of performance-based financing in low- and lower middleincome countries: a review of the literature. Health Policy Plan, 2016a. doi: 10.1093/heapol/czw045.

RENMANS, Dimitri et al. Opening the 'black box' of performance-based financing in low- and lower middleincome countries: a review of the literature. Health Policy Plan 31 (9):1297-309. doi: 10.1093/heapol/czw045, 2016b.

RUDASINGWA, Martin; SOETERS, Robert; BASENYA, Oliver. The effect of performance-based financing on maternal healthcare use in Burundi: a two-wave pooled cross-sectional analysis. Glob Health Action 10 (1):1327241, 2017. doi: 10.1080/16549716.2017.1327241.

RUDASINGWA, Martin; SOETERS, Robert; BOSSUYT, Michel. The effect of performance-based financial incentives on improving health care provision in Burundi: a controlled cohort study. Glob J Health Sci 7 (3):1529, 2014. doi: 10.5539/gjhs.v7n3p15.

RUSA, Louis et al. Performance-based financing for better quality of services in Rwandan health centres: 3-year experience. Trop Med Int Health 14 (7):830-7, 2009. doi: 10.1111/j.1365-3156.2009.02292.x. 
The Good, the Bad, and the Disruptive of Performance-Based Financing on the Mozambican Health System: Results from a process

Jessica Gergen (ThinkWell); Yogesh Rajkotia (ThinkWell); Nirmala Ravishankar (ThinkWell).

SEPPEY, Mathieu et al. Donor-funded project's sustainability assessment: a qualitative case study of a results-based financing pilot in Koulikoro region, Mali. Global Health 13 (1):86, 2017. doi: 10.1186/s12992-017-0307-8.

SHROFF, Cyrus Zubin; BIGDELI, Monsen; MEESSEN, Bruno. From Scheme to System (Part 2): Findings from Ten Countries on the Policy Evolution of Results-Based Financing in Health Systems. Health Systems \& Reform 3 (2), 2017. doi: http://dx.doi.org/10.1080/23288604.2017.1304190.

SKILES, Martha Priedeman et al.The effect of performance-based financing on illness, care-seeking and treatment among children: an impact evaluation in Rwanda. BMC Health Serv Res 15:375. doi: 10.1186/s12913-0151033-7, 2015.

SOUCAT, Agnes et al. Pay-for-Performance Debate: Not Seeing the Forest for the Trees. Health Systems \& Reform 3 (2):74-79, 2017.

THE WORLD BANK GROUP. Results-based Financing for Health, Country Performance Portal. RBF Health. Available at: https://www.rbfhealth.org/.Accessed in 12/1/2017.

TONNEN, Jonnen; VAN DER WAL, Bertram. Results-based Financing in Healthcare. Developing an RBF Approach for Healthcare in Different Contexts:The Case of Mali and Ghana.Amsterdam: KIT Publishers, 2012.

THE AIDSTAR-TWO PROJECT. The PBF Handbook: Designing and Implementing Effective PerformanceBased Financing Programs.Version 1.0. Cambridge: Management Sciences for Health, 2011. Available at https:// www.msh.org/sites/msh.org/files/pbf_handbook_english_edited_2016.pdf. Accessed in 01/12/2017.

TURCOTTE-TREMBLAY, Anne-Marie et al. The unintended consequences of community verifications for performance-based financing in Burkina Faso. Soc Sci Med 191:226-236. doi: 10.1016/j.socscimed.2017.09.007, 2017.

TURCOTTE-TREMBLAY, Anne-Marie et al. Does performance-based financing increase value for money in low- and middle- income countries? A systematic review. Health Econ Rev 6 (1):30. doi: 10.1186/s13561-0160103-9, 2015.

UNIVERSITY RESEARCH CO., LLC, and THINKWELL. Quality of Care in Performance-Based Incentives in Democratic Republic of Congo, Mozambique, and Nigeria.: USAID Translating Research into Action, 2016.

VAN DE POEL, Elizabeth et al. Impact of Performance-Based Financing in a Low-Resource Setting: A Decade of Experience in Cambodia. Health Econ 25 (6):688-705. doi: 10.1002/hec.3219, 2016.

WITTER, Sophie et al. Paying for performance to improve the delivery of health interventions in low- and middleincome countries. Cochrane Database Syst Rev (2):CD007899, 2012. doi: 10.1002/14651858.CD007899.pub2.

WITTER, Sophie et al. Performance-based financing as a health system reform: mapping the key dimensions for monitoring and evaluation. BMC Health Serv Res 13:367. doi: 10.1186/1472-6963-13-367, 2013.

WORLD HEALTH ORGANIZATION.The WHO Health Systems Framework, 2012. https://www.who.int/ healthsystems/strategy/en/. Accessed on 1/12/2017. 


\section{O Bom, o Mau e o Desequilíbrio do Financiamento Baseado em Desempenho no Sistema de Saúde de Moçambique: resultados de uma avaliação de processo}

\section{Resumo}

Tem sido significativamente debatido se o Financiamento Baseado em Desempenho (FBD) é um mecanismo para alcançar uma transformação mais ampla dos sistemas de saúde. Este estudo pretende contribuir para esse diálogo ao analisar a forma como o FBD promoveu efeitos positivos, perversos e disruptivos sobre o sistema de saúde em duas províncias de Moçambique. Este estudo utilizou métodos qualitativos de coleta de dados em 24 unidades de saúdeque implementam oFBD, de mais de 60 profissionais de saúde e administradores das unidades. O PBF melhorou as unidades de saúde e oambiente de trabalho das instalações por meio do aumento da autonomia e da capacidade fiscal local, resultando em mais planejamento. Os trabalhadores da saúde perceberam os incentivos como uma fonte de motivação, no entanto, a alocação de incentivos entre os funcionários foi injusta e sem transparência. Melhorias na qualidade e completude dos dados foram observadas nos registros cadastrais, verificados trimestralmente. Porém, uma carga de trabalho mais pesada e um maior aprimoramento nos sistemas de informação prejudicaram o tempo gasto em atendimento clínico. A manutenção de efeitos positivos exigirá maior foco na institucionalização de mudanças na governança, nas estruturas de gestão e na autonomia fiscal, ao mesmo tempo em que aumentará a inclusão do lado da demanda.

Palavras-chave: Financiamento baseado em desempenho, financiamento baseado nos resultados, sistemas de saúde, Moçambique, reforma de sistemas de saúde.

\section{Lo bueno, lo malo y lo perturbador del financiamiento basado en el desempeño en el sistema de salud de Mozambique: resultados de una evaluación del proceso}

\section{Resumen}

Se ha debatido considerablemente si la financiación basada en el rendimiento (FBD) es un mecanismo para lograr una transformación más amplia de los sistemas sanitarios. Este estudio pretende contribuir a ese diálogo, al analizar la forma en que el FBD promovió efectos positivos, perversos y disruptivos sobre el sistema de salud en dos provincias de Mozambique. Este estudio utilizó métodos cualitativos de recolección de datos en 24 unidades de salud que implementan el FBD, de más de 60 profesionales de salud y administradores de las unidades. El PBF mejoró las unidades de salud ambiente de trabajo de las instalaciones a través del aumento de la autonomía y la capacidad fiscal local, resultando en más planificación. Los trabajadores de la salud percibieron incentivos como una fuente de motivación, sin embargo, la asignación de incentivos entre los funcionarios fue injusta y sin transparencia. Las mejoras en la calidad y la completitud de los datos se observaron en los registros catastrales, verificados trimestralmente. Sin embargo, una carga de trabajo más pesada y mayor dada al mejorado en los sistemas de información perjudicaron el tiempo que se gastó en atención clínica. El mantenimiento de efectos positivos requerirá un mayor enfoque en la institucionalización de cambios en la gobernanza, en las estructuras de gestión y en la autonomía fiscal, al tiempo que aumenta la inclusión del lado de la demanda. 
The Good, the Bad, and the Disruptive of Performance-Based Financing on the Mozambican Health System: Results from a process

evaluation

Jessica Gergen (ThinkWell); Yogesh Rajkotia (ThinkWell); Nirmala Ravishankar (ThinkWell).

Palabras clave: Financiamiento basado en el desempeño, financiamiento basado en los resultados, sistemas de salud, Mozambique, reforma de sistemas de salud.

Received: $16 / \mathrm{Apr} / 2018$

Approved $^{1}:$ 24/Aug/2018

\section{Availability of data and material}

The dataset(s) supporting the conclusions of this article are considered sensitive. The datasets are owned by the United States Center for Disease Control and Prevention. Registration of the study has been completed through the CDC data repository. Analytical files and presentation of the findings have been shared with the Mozambican Ministry of Health.

Funding:This study is funded by the Presidents' Emergency Program for AIDS Relief (PEFPAR) through the Centers for Disease Control and Prevention (CDC), Project Fortalecer Cooperative Agreement U2GGH000422-01.

Disclaimer: The findings and conclusions in this report are those of the author(s) and do not necessarily represent the official position of the Centers for Disease Control and Prevention.

Ethical Trial Registration: Ethical approval for the study protocol, data collection instruments and informed consent forms was obtained from the Ethics Review Committee of the Centers for Disease Control and Prevention (CDC) [IRB 2015-190], and the Ethics Review Committee of the Mozambique Ministry of Health.

Acknowledgements: We would also like to thank all health care providers, managers and community health advocates who took the time to speak with our team and helped to inform these findings.

Author Contributions: Conceived and designed study: JG, YR. Performed data collection: JG. Analyzed the data:JG, NR. Wrote the paper:JG, NR,YR. 